\title{
Investigation on Metamaterial Antenna for Terahertz Applications
}

\author{
Amalraj Taksala Devapriya (1), Savarimuthu Robinson \\ Department of Electronics and Communication Engineering, Mount Zion College of Engineering and \\ Technology, Chennai \\ taksala@gmail.com,mail2robinson@gmail.com
}

\begin{abstract}
In this paper, the metamaterial based rectangular microstrip patch antenna is proposed and designed for $\mathrm{THz}$ applications. The circular split ring resonator is implemented as metamaterial. By incorporating metamaterial in the conventional microstrip patch antenna, the size is reduced and the performance of antenna is improved. The proposed antenna has the dimensions of $180 \times 212 \times 10 \mu^{3}$ which is designed on Quartz substrate which is fed by microstrip line feed technique. Additionally, the performance of the metamaterial antenna is analyzed by varying unit cell gap size and thickness. The antenna resonates at $1.02 \mathrm{THz}$ which gives the return loss of $-65 \mathrm{~dB}$. Thus, the proposed antenna can be utilized in $\mathrm{THz}$ region.
\end{abstract}

Index Terms - Metamaterial, Terahertz region

\section{INTRODUCTION}

Recent years, there is a demand on the unallocated frequency spectrum, the future communication systems focus on $\mathrm{THz}$ region for increased carrier frequency, higher data rates and high channel capacity [1]. $\mathrm{THz}$ is quite suitable to develop a current generation wireless telecommunication system, which can fire at a blazing fast speed of $100 \mathrm{~Gb} / \mathrm{sec}$. This utility of $\mathrm{THz}$ technique is quite promising for high-speed information transmission between electronic devices. Terahertz radiation gives a more engaged flag that could enhance the performance and reduce the power utilization of mobile towers. One of the key features of $\mathrm{THz}$ radiation is that many materials which block visible and IR spectra, that reveal to be transparent in $\mathrm{THz}$ frequency range. $\mathrm{THz}$ frequency range allows achieving a fairly good spatial resolution required for rendering quality imaging.

Since $\mathrm{THz}$ wave has shorter wavelengths than microwaves it suffers by high free space path loss and high atmospheric attenuation. This free space path loss can be overcame by using antenna with high directivity and high gain. However, to transmit this shorter wavelength signals miniaturized antennas are needed [2]. Microstrip patch antennas will meet all these requirements, because of its ease of installation, low cost and small size. The simple mechanism to improve the gain of the patch antenna is implementing metamaterial surface [3]. Especially the circularly polarized patch antenna has the ability to reduce the multipath effects [4]. Hence, radiation from these antennas are not depending on the orientation of transmitter and receiver. In order to reduce size, weight, and cost, there has been a growing interest in planar structures [5]. Patch antennas are incorporated with the 
artificial metamaterials that have negative refractive index thus enable antenna miniaturization. Graphene layer over the dielectric substrate [6] can also be used as perfect absorbing element [7] in thermally based $\mathrm{THz}$ imaging devices [8], [9], because graphene resistivity decreases with the increase of electrostatic voltage [10]. Split-ring resonators (SRRs) have been the most commonly used meta-atom unit cell design at the microwave and terahertz frequencies [11]. The synergetic effect of both components of the composite (e.g., the MOFs and CNTs/ GO/ NPs/ biomolecules) should lead to an improvement in the electrocatalytic sensing of different species [12]. In THz region, metamaterial substrate enhances the performance of antenna by reflecting the signal in desired direction [13], and metamaterial substrate based on complimentary split ring resonator improves the impedance bandwidth [14]. The resonance of this metamaterials can be turned on/off by changing the capacitance of SRR [15], [16]. The array of resonators is able to decrease the resonance frequency and increase the realized gain of the antenna [17]. The utilization of the metamaterials in $\mathrm{THz}$ region have lot of applications including filters, observers, switches and modulators [18]. THz technology may be applied for the understanding of brain function in health and disease by providing biochemical profiling of various neurotransmitters in various conditions [19].

Recently, there has been growing interest in the design of metamaterial antenna. Many studies are done to analyze the common antenna parameters such as return loss, gain, directivity, VSWR and radiation pattern. Denizhan Sirmaciet et al. designed fishnet based metamaterial as a defected ground to enhance the bandwidth and return loss of the patch antenna. They achieved the bandwidth of $8.2 \%$ and return loss of $-55 \mathrm{~dB}$ at $1.08 \mathrm{THz}$ [1]. Pai-Yen Chen et al. investigated the tunable $\mathrm{THz}$ metamaterial consisting of graphene surface above the grounded surface. They suggested that this graphene can be used as the alternative design of the artificial metamaterial [6]. Jeet Ghosh et al. proposed the graphene metasurface which is implemented over the polysilicon layer and can be used to reduce the mutual coupling in the closely packed antenna array [7]. Zheng $\mathrm{Xu}$ et al. designed the graphene based MIMO antenna for THz communication. They examined that the proposed antenna has high spectral efficiency than the conventional MIMO antennas [10]. Maria Koutsoupidou et al. proposed $\mathrm{THz}$ antenna with four different type of split ring resonator (SRR) based metamaterial such as metasurface with single SRR, SRR with cross shaped structure, SRRs of linearly decreasing side length and SRRs of decreasing dimensions with a parabolic function. They analyzed that the metasurface with single SSR and SRRs of linearly decreasing side length produce better return loss at $1.3 \mathrm{THz}$ and $1 \mathrm{THz}$, respectively [13]. Yoonjae Lee et al. proposed the design of compact high gain patch antenna using complementary split ring resonator (CSRR) as metamaterial surface. They used two different materials with different permittivity. They analyzed that the CSRR loaded on high permittivity surface improves the antenna performance over the $\mathrm{THz}$ region [14].

Ho-Jin Song et al propose one more type of $\mathrm{THz}$ antenna, which is implemented overSi-based substrate such as CMOS and SiGe. They reported $\mathrm{THz}$ waves could support data rates of $10 \mathrm{~Gb} / \mathrm{s}$. However, progress in speed is quite low [20]. Ameneh Nejati et al. designed patch antenna on Pyrex Brazilian Microwave and Optoelectronics Society-SBMO received 27 Dec 2018; for review 27 Dec 2018; accepted 4 July 2019 Brazilian Society of Electromagnetism-SBMag 
material at $\mathrm{THz}$ range with frequency selective surface and photonic band gap structures. The proposed antenna has dimensions of $500 \mu \mathrm{m} \times 500 \mu \mathrm{m} \times 10 \mu \mathrm{m}$ and the gain is increased by $2 \mathrm{dBi}$ (32\%) [21]. Yanbing Ma et al designed Square Sierpinski SRR (SS-SRR) for terahertz sensing application. They investigated the frequency response when the SS-SRR is implemented over the quartz substrate with the thickness as $130 \mu \mathrm{m}$ [22]. Pozar et al. designed and analyzed two types of printed antennas for millimeter wave communication such as patch and dipole. He suggested that substrate materials like polytetrafluoroethylene, quartz and gallium arsenide [23].

Par et al. proposed the new idea of $\mathrm{THz}$ wave transmission over the slot antennas on various dielectric substrates. They reported that the resonance frequency of the $\mathrm{THz}$ transmission is shifted due to the changes in substrate refractive index [24]. Sae June Park et al. analyzed the performance of the $\mathrm{THz}$ antenna by changing the gap width of the metamaterial. They reported that when the metamaterial gap width decreased, the vertical range of metamaterial detection volume decreased [25].

Le et al. implemented the planar metamaterial surface on both upper patch and bottom ground to improve the performance of the antenna. They designed a conventional antenna in the size of $12 \mathrm{~mm}$ $\times 16 \mathrm{~mm}$. Maximum gain of $7.14 \mathrm{~dB}$ is achieved [26]. Gohar et al. designed fractal antenna and metamaterial based patch antenna to improve the antenna performance. The metamaterial based antenna with the size of $40 \mathrm{~mm} \times 40 \mathrm{~mm}$ resonates at 2.4, 3.5 and $5 \mathrm{GHz}$. They achieved $24 \%$ of antenna miniaturization by the metamaterial unit cell [27]. Pankaj et al. designed log periodic with metamaterial. Metamaterial structure is a 2-D array of Square Spit-Ring Resonators. Maximum gain of $9.991 \mathrm{~dB}$ at $4.521 \mathrm{THz}$ was achieved [28]. Adel et al. proposed the design of LH-MTM terahertz patch antenna. Metamaterial consists of SRR and thin wires. Gain, bandwidth and return loss were improved as $1.1 \mathrm{~dB}, 14.73 \mathrm{GHz}$ and $12.62 \mathrm{~dB}$ respectively [29]. Qing et al. proposed a design of $\log$ periodic antenna with fishnet metamaterial. Antenna loaded with low refractive index metamaterial was analyzed at $0.339 \mathrm{THz}, 0.340 \mathrm{THz}$ and $0.341 \mathrm{THz}$. Maximum gain is $7.5 \mathrm{~dB}$ at $0.339 \mathrm{THz}$ [30]. Mukesh et al. designed split ring resonator in four different shapes. They analyzed the characteristics on the FR4 substrate at $4.409 \mathrm{GHz}, 4.249 \mathrm{GHz}, 4.139 \mathrm{THz}$ and $3.833 \mathrm{THz}$. They achieved the compactness of $3.63 \%, 6.13 \%$ and $13.06 \%$ at $4.249 \mathrm{GHz}, 4.139 \mathrm{THz}$ and $3.833 \mathrm{THz}$ respectively [31].

From the literature survey, it is observed that designing the $\mathrm{THz}$ antenna performance improvement and miniaturization in size are the major challenges. In this paper, similar to other promising studies existing in literature, the metamaterial based $\mathrm{THz}$ antenna is designed. Conventional patch antenna with the size of $71.5 \mu \mathrm{m} \times 95 \mu \mathrm{m}$ is proposed and circular shaped SRR structure is loaded in the ground plane. The functional parameters of the antenna are investigated by varying the split width and split ring thickness of the metamaterial.

The paper is organized as follows: In section II design and performance of microstrip patch antenna is discussed. The metamaterial unit cell structure and SRR design is discussed in section III. In section Brazilian Microwave and Optoelectronics Society-SBMO received 27 Dec 2018; for review 27 Dec 2018; accepted 4 July 2019 $\begin{array}{llll}\text { Brazilian Society of Electromagnetism-SBMag } & \text { C } 2019 \text { SBMO/SBMag } & \text { (cc) BY } \\ \text { ISSN 2179-1074 }\end{array}$ 
IV simulation results are presented after loading metamaterials on the patch. The section V describes the conclusion of the paper.

\section{PATCH ANTENNA DESIGN}

The structure of the proposed rectangular microstrip patch antenna is shown in Fig. 1. The antenna is designed with the dimensions of $131.5 \mu \mathrm{m} \times 155 \mu \mathrm{m} \times 10 \mu \mathrm{m}$. The patch antenna is designed on quartz dielectric material with dielectric constant 3.78 and the loss tangent of about 0.001. Radiating patch has the dimensions as $71.5 \mu \mathrm{m} \times 95 \mu \mathrm{m}$. The layout consists of substrate, feed line and radiating patch. A rectangular patch is fed by a way of microstrip inset technique. The microstrip feed line is located $41 \mu \mathrm{m}$ away from one end of the patch whose length and width are $83 \mu \mathrm{m}$ and $24 \mu \mathrm{m}$, respectively. The feed line is inset to the patch with the value of slot length as $39 \mu \mathrm{m}$ and slot width as $4.75 \mu \mathrm{m}$ on each side of the feed line. The current is low at the ends of a half-wave patch and increases in magnitude towards the center, the input impedance could be reduced if the patch was fed closer to the center. In the proposed design, the feed is slightly away from the center for impedance matching. By adjusting the feed location along the circumference of the patch it is possible to match the antenna with a microstrip line of any impedance. Hence, the feeding is displaced from center. The detailed geometrical parameters of patch antenna are shown in Table I. The performance of the rectangular microstrip patch antenna depends on its dimensions. The proposed structure is designed and simulated by using Finite Element Method (FEM).

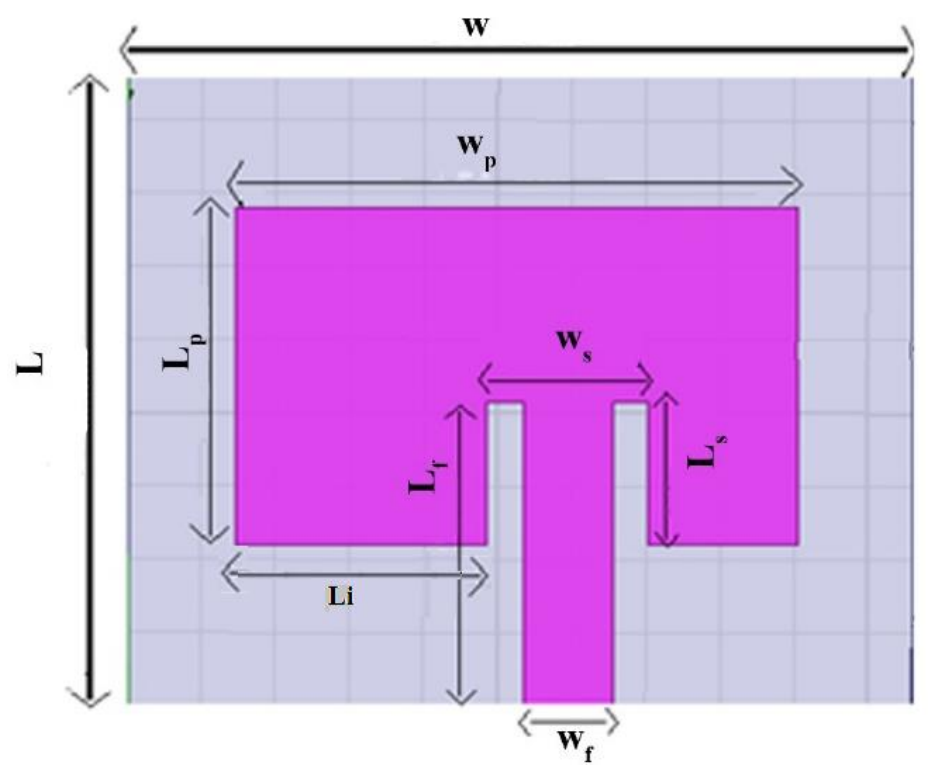

Fig. 1. Structure of the proposed microstrip patch antenna. 


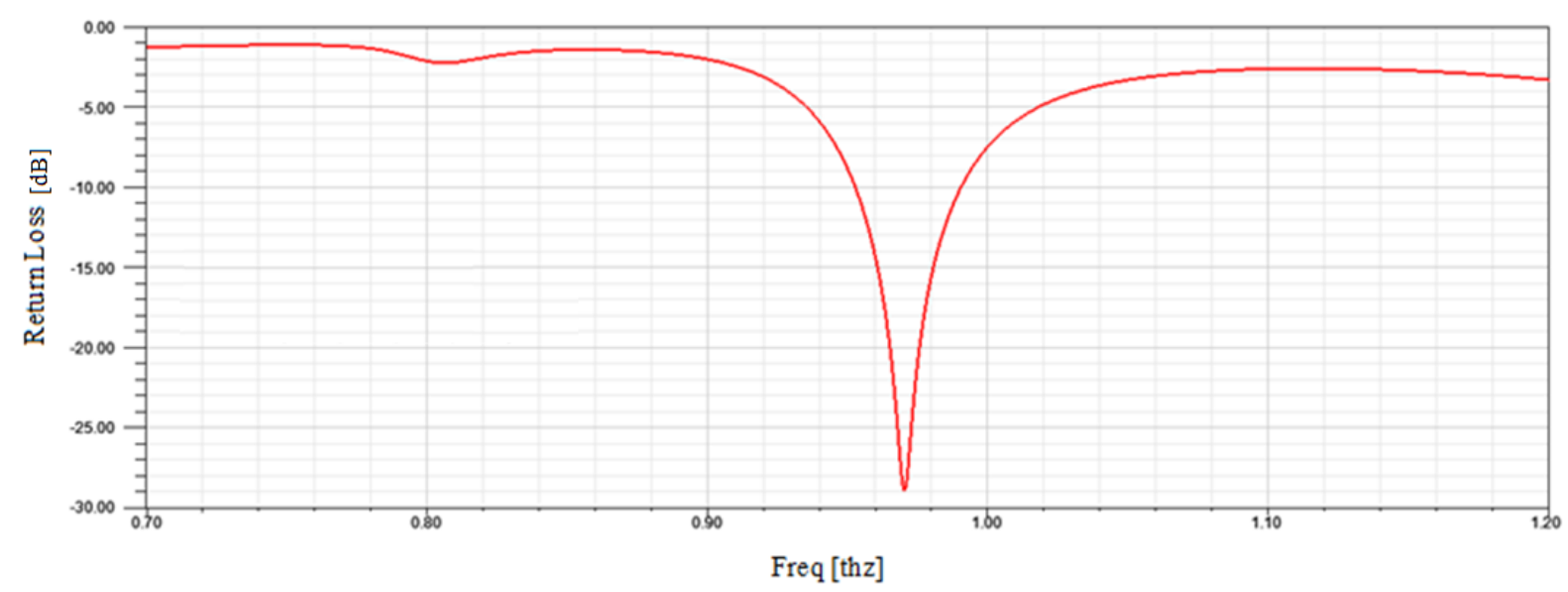

Fig. 2. Return loss for proposed patch antenna.

The proposed antenna has the resonance frequency of $0.97 \mathrm{THz}$. Generally, return loss indicates that the amount of power that does not return as reflection. The return loss of the proposed antenna without metamaterial structure is shown in Fig. 2. The proposed antenna has the better return loss (at least $-10 \mathrm{~dB}$ ) at frequencies from $0.96 \mathrm{THz}$ to $0.99 \mathrm{THz}$. The antenna without metamaterial resonates at $0.97 \mathrm{THz}$ and it produces the return loss as $-28.76 \mathrm{~dB}$. The fractional bandwidth of $4.12 \%$ is achieved.

\begin{tabular}{|c|c|}
\hline Parameters & Dimensions $(\mu \mathrm{m})$ \\
\hline Substrate length (L) & 180 \\
\hline Substrate width (W) & 212 \\
\hline Substrate thickness (t) & 10 \\
\hline Patch length $\left(\mathrm{L}_{\mathrm{P}}\right)$ & 75 \\
\hline Patch width $\left(\mathrm{W}_{\mathrm{p}}\right)$ & 100 \\
\hline Slot length $\left(\mathrm{L}_{\mathrm{s}}\right)$ & 39 \\
\hline Slot width $\left(\mathrm{W}_{\mathrm{s}}\right)$ & 43.5 \\
\hline Inset feed length $\left(\mathrm{Lf}_{\mathrm{f}}\right)$ & 83 \\
\hline Inset feed width $\left(\mathrm{W}_{\mathrm{f}}\right)$ & 24 \\
\hline Feed location (Li) & 41 \\
\hline
\end{tabular}

\section{METAMATERIAL UNIT CELL DESIGN}

The circular shaped Split Ring Resonator (SRR) is used to construct the metamaterial surface. Fig. 3 (a) shows unit cell structure of circular SRR. The metallic part is printed on quartz substrate. The geometrical parameters of proposed SRR in Table II. The proposed SRR consists of two annular rings with outer radius of $20 \mu \mathrm{m}$ and inner radius of $15 \mu \mathrm{m}$. The split width is taken as $5 \mu \mathrm{m}$ and split ring thickness are $5 \mu \mathrm{m}$. Meta surface is constructed by arranging the circular SSR on the ground plane as shown in Fig. 3(b). The permeability and permittivity of the proposed circular SRR can be calculated directly by using the following equations [32], [33]:

$$
\begin{aligned}
& \mu=n z \\
& \xi=n / z
\end{aligned}
$$


where $n$ is the refractive index and $Z$ is the impedance.

The $\mathrm{S}$ parameters can be related with refractive index and impedance by

$$
\begin{gathered}
Z=\sqrt{\frac{\left(1+S_{11}\right)-S_{21}^{2}}{\left(1-S_{11}\right)-S_{21}^{2}}} \\
n=\frac{1}{k d} \cos ^{-1}\left[\frac{\left(1-S_{11}^{2}+S_{12}^{2}\right)}{2 S_{12}}\right]
\end{gathered}
$$

Here, $K$ and $d$ denote the wave number of incident wave and SRR length respectively. Further, the value of refractive index $n$ and impedance $Z$ are determined by using (3) and (4).

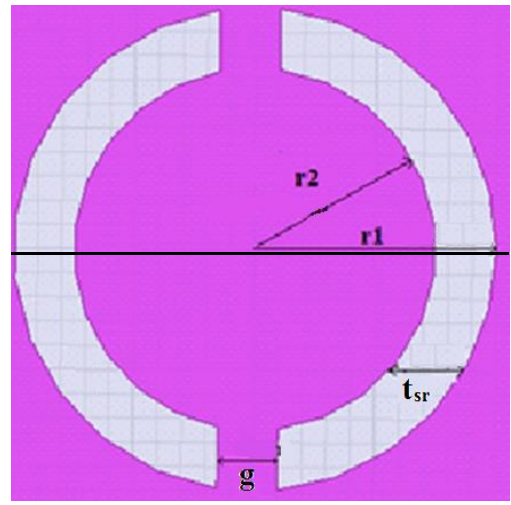

(a)

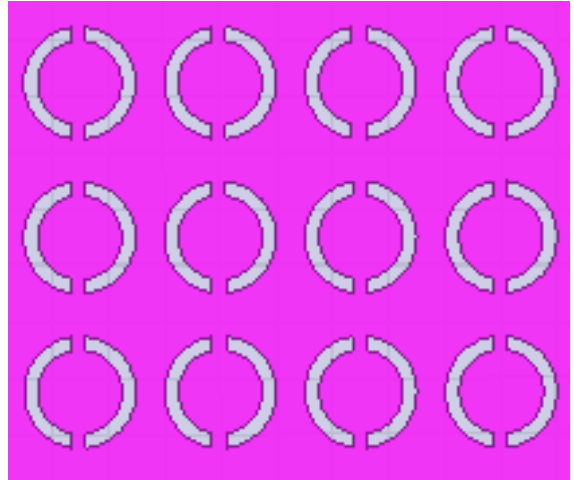

(b)

Fig. 3. Schematic representation of Circular split ring resonator (a) unit cell and (b) $3 \times 4$ unit cell formation.

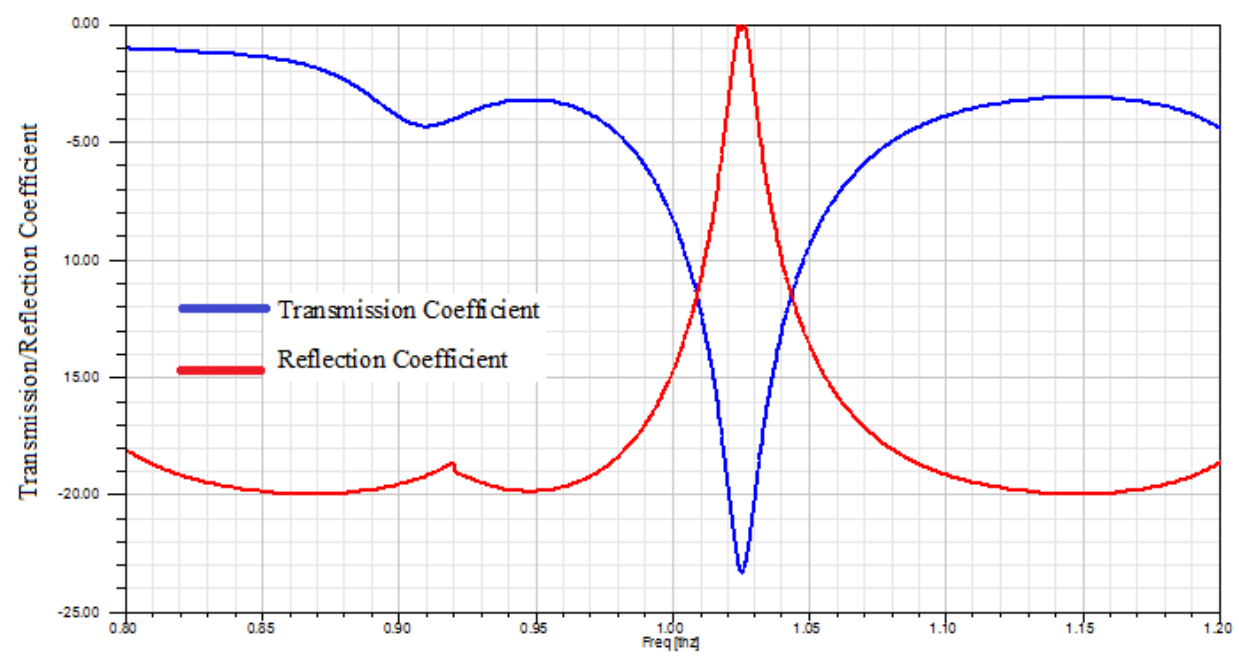

Fig. 4. Reflection and Transmission coefficient of Circular split ring resonator. 


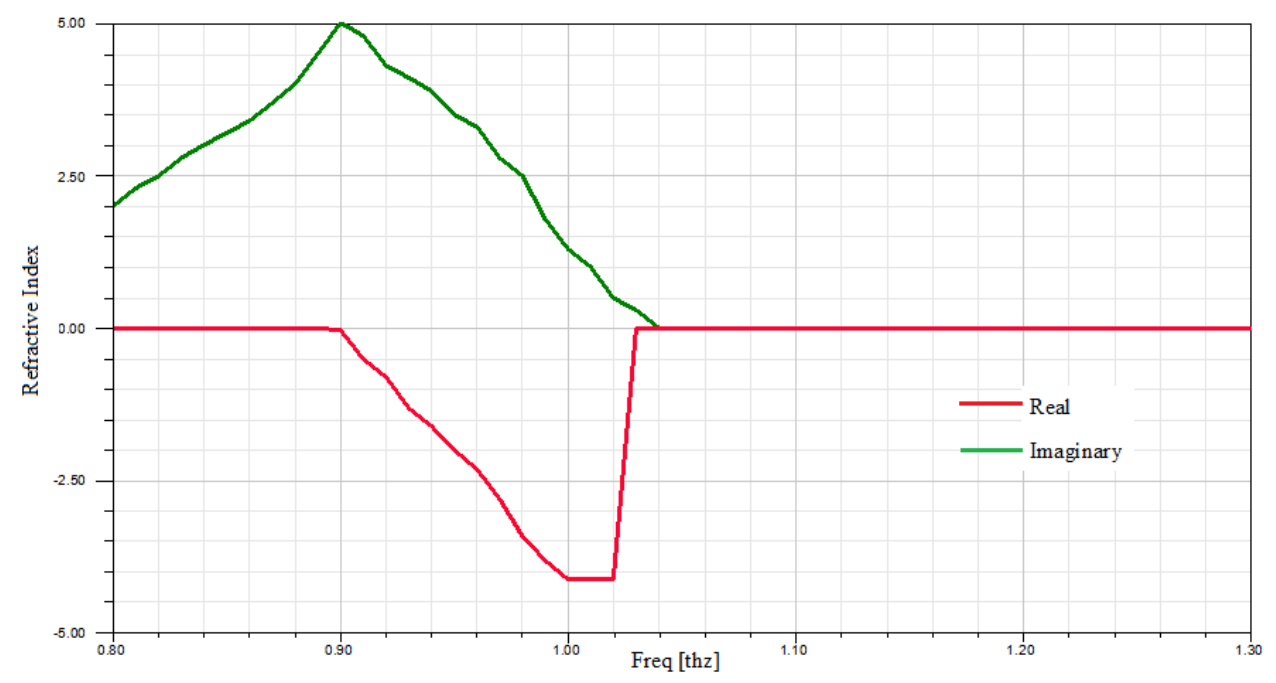

Fig. 5. Refractive index of Circular split ring resonator.

Reflection coefficient and transmission coefficient of the SRR is shown in Fig. 4. Generally, the transmission coefficient reaches minimum value in the resonance frequency of the SRR [1], [21], [24], [33], [34]. The transmission curve deeps at the frequency of $1.027 \mathrm{THz}$ at the same point the reflection curve reaches its maximum. This indicates there is a resonance at $1.02 \mathrm{THz}$. Each unit cell is periodically arranged to behave as a microwave resonant circuit. The capacitance is made by the adjacent unit cells, which could be altered by varying the size of the unit cell. The periodic arrangement of these LC resonant elements is parameterized to significantly block surface wave's around the resonant frequency. Hence, the proposed unit cell provides negative permittivity and negative permeability around the resonance frequency. A capacitor-like 'split'structure regarded with a capacitance $(\mathrm{C})$ couples to the electric field, and the two rings of the eSRR provide an inductance (L) to the circuit. Hence, the resonance frequency of the SRR can be changed either by varying the dimensions of the rings to alter the qualitative inductance or by varying the split to adjust the qualitative capacitance [35]. The proposed split ring resonator has negative refractive index at this resonance frequency, which is shown in Fig. 5. Due to the negative refractive index value, the metamaterial produces negative permittivity and negative permeability. The resonance frequency of the SRR purely depends on its size. By having splits in the rings, the SRR unit can be made resonant at wavelengths much larger than the diameter of the rings; that is, there is no half-wavelength requirement for resonance, as would be the case if the rings were closed [36]. The coupling effects between SRRs can be achieved by varying lattice arrangements of the meta-atoms. A SRR can be regarded as a LC circuit, its resonant frequency can then be simplified as $\omega_{L C}=\sqrt{\frac{2}{L C}}$ [37]. 
Journal of Microwaves, Optoelectronics and Electromagnetic Applications, Vol. 18, No. 3, September 2019384 DOI: http://dx.doi.org/10.1590/2179-10742019v18i31577

TABLE II. Geometrical PaRAmeters of Unit Cell

\begin{tabular}{lc}
\hline \multicolumn{1}{c}{ Parameters } & Dimensions $(\boldsymbol{\mu m})$ \\
\hline Radius of the outer circle $\left(\mathrm{r}_{1}\right)$ & 20 \\
Radius of the inner circle $\left(\mathrm{r}_{2}\right)$ & 15 \\
Split ring Thickness $\left(\mathrm{t}_{\mathrm{sr}}\right)$ & 5 \\
Split width $(\mathrm{g})$ & 5 \\
\hline
\end{tabular}

\section{RESULTS AND DISCUSSIONS}

The designed metamaterial structure is loaded on the substrate of the proposed $\mathrm{THz}$ antenna whose dimension is $68.5 \times 90 \mu \mathrm{m}^{2}$. Front and back view of proposed $\mathrm{THz}$ antenna with metamaterial is shown Fig. 6(a) and 6(b), respectively. The antenna with metamaterial is simulated and its results are shown in Fig. 7. It is noticed that the antenna with metamaterial resonates at $1.02 \mathrm{THz}$. Since the metasurface is designed to resonate at $1.02 \mathrm{THz}$ the resonance frequency of the antenna with metamaterial is shifted to $1.02 \mathrm{THz}$ [1], [14]. It seems that the size of the antenna is also reduced. Also, the return loss is further reduced as $-65.26 \mathrm{~dB}$ at $1.02 \mathrm{THz}$. When the MTM is loaded with substrate this left handed material will act as reflecting surface and it will focus the maximum radiation energy in the desired direction. Also, it suppresses the surface wave of the antenna hence the return loss is highly improved. Gain of the proposed antenna with and without metamaterial are shown in Fig. 8(a) and 8(b) respectively. It is observed that the proposed antenna after incorporating metamaterial has the maximum gain of $5.75 \mathrm{~dB}$.

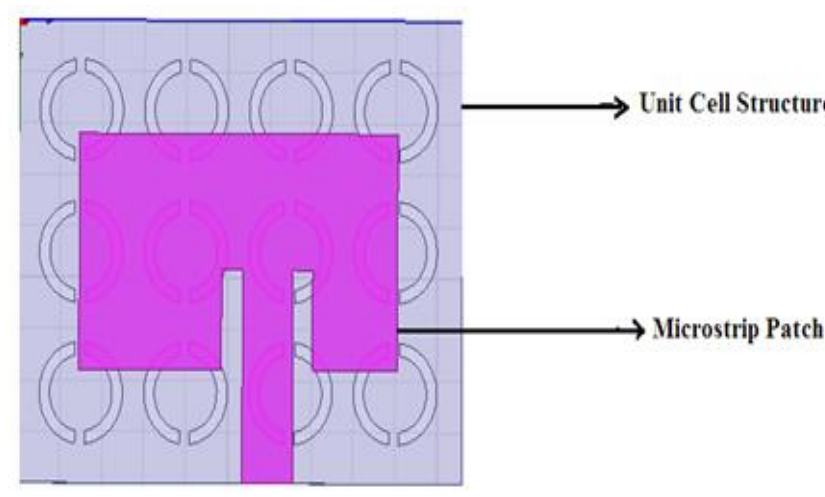

(a)

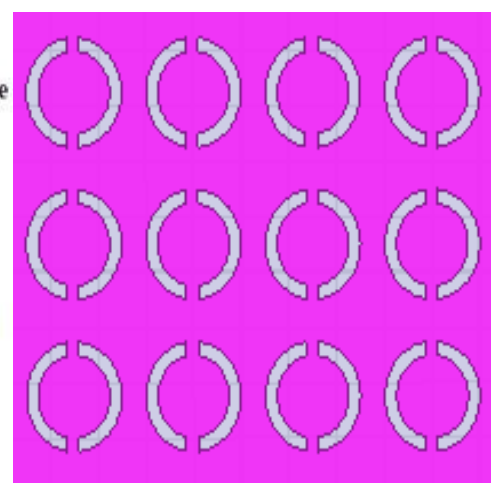

(b)

Fig. 6. (a) Front view and (b) Back view of proposed antenna with MTM. 


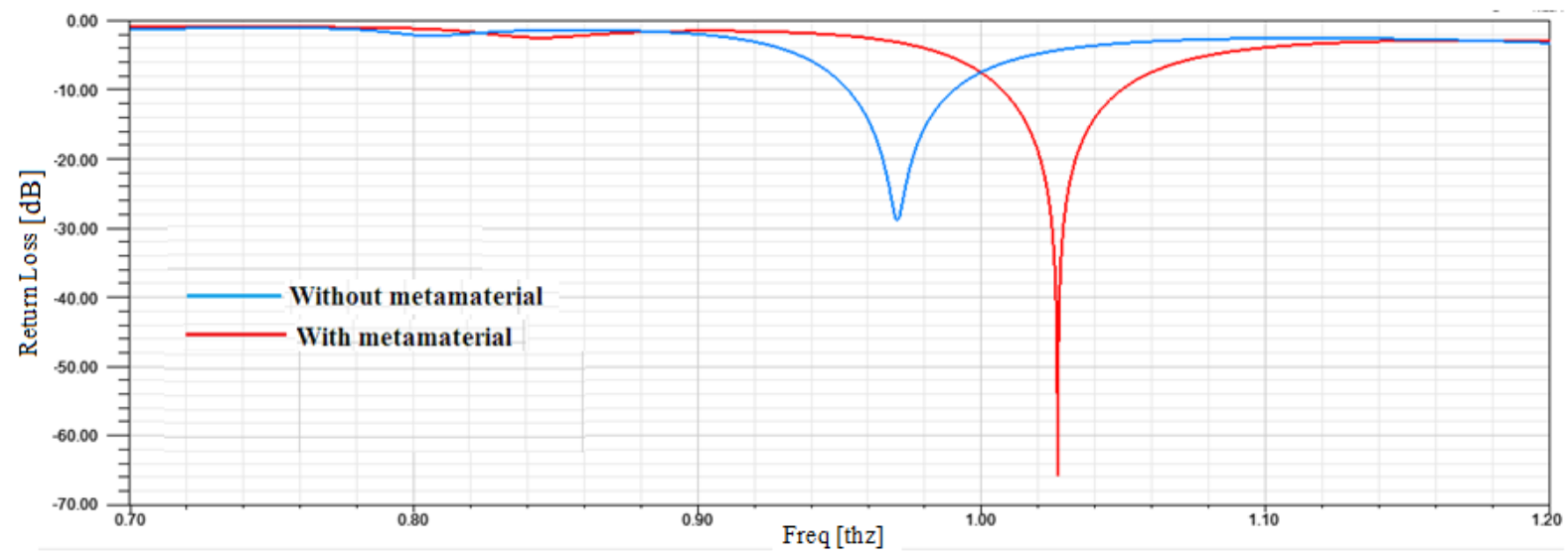

Fig. 7. Return loss of the proposed antenna with and without MTM.

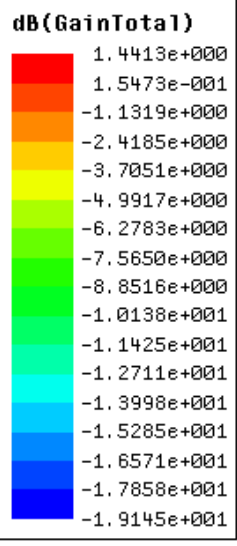

(a)
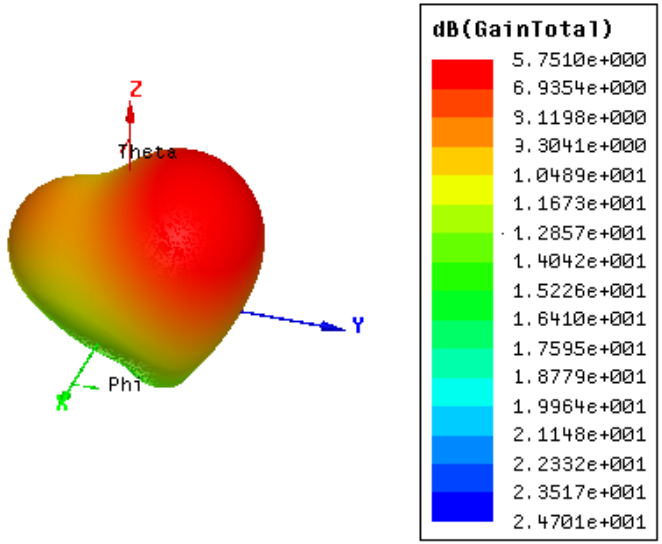

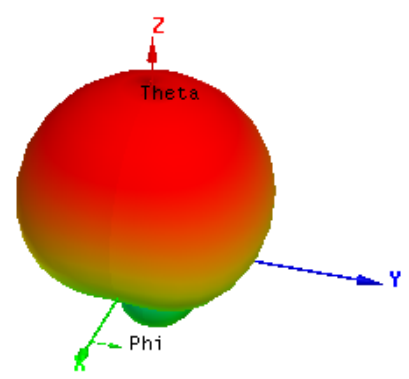

(b)

Fig. 8. Gain of an antenna (a) without MTM (b) with MTM.

The conventional patch is produced the maximum gain of $1.44 \mathrm{~dB}$. It is clearly noticed that, the MTM helps to radiate maximum radiation energy in the desired direction. Hence the directivity and gain are enhanced, but there is no change in bandwidth, the fractional bandwidth is maintained as $4.12 \%$. Further, the performance of the antenna is analyzed by varying the ring width and split width in the metamaterial. Here six different split widths with a dimension of $2 \mu \mathrm{m}, 3 \mu \mathrm{m}, 4 \mu \mathrm{m}, 6 \mu \mathrm{m}, 7 \mu \mathrm{m}$, $8 \mu \mathrm{m}$ are analyzed and its performance is shown in Fig. 9. The variation in resonant frequency, return loss and VSWR while changing the split width is listed in Table. III.

It is noted that the operating frequency is shifted slightly with respect to the split width. Normally, the resonance frequency of the metamaterial depends on both inductance and capacitance of the metasurface. Current path of SRR affects the inductance value and the capacitance is determined by both split width and dielectric constant of the substrate [14], [17]. When the split width is small high capacitance will be produced. Resonant frequency of the ring is inversely proportional to the value of ring capacitance. When the split width is $5 \mu \mathrm{m}$ maximum return loss of $-65 \mathrm{~dB}$ and for $4 \mu \mathrm{m}$ split width $-50.16 \mathrm{~dB}$ of return loss is achieved. 
Journal of Microwaves, Optoelectronics and Electromagnetic Applications, Vol. 18, No. 3, September 2019386 DOI: http://dx.doi.org/10.1590/2179-10742019v18i31577

TABLE III. RESONANT FREQUENCY, RETURN LOSS AND VSWR FOR DIFFERENT SPLIT WIDTH OF CIRCULAR SPLIT RING RESONATOR

\begin{tabular}{cccc}
\hline $\begin{array}{c}\text { Split Width } \\
\text { size } \\
(\boldsymbol{\mu m})\end{array}$ & $\begin{array}{c}\text { Frequency } \\
\text { (THz) }\end{array}$ & $\begin{array}{c}\text { Return Loss } \\
(\mathbf{d B})\end{array}$ & VSWR \\
\hline 2 & 1.021 & -33.71 & \\
3 & 1.023 & -30.48 & 1.02 \\
4 & 1.025 & -50.16 & 1.26 \\
$\mathbf{5}$ & $\mathbf{1 . 0 2 7}$ & $\mathbf{- 6 5 . 2 6}$ & $\mathbf{1 . 0 2}$ \\
6 & 1.025 & -39.17 & 1.04 \\
7 & 1.024 & -33.71 & 1.01 \\
8 & 1.021 & -44.62 & 1.02 \\
\hline
\end{tabular}

TABLE IV. RESONANT FREQUENCY, RETURN LOSS AND VSWR FOR DIFFERENT RING WIDTH OF CIRCULAR SPLIT RING RESONATOR

\begin{tabular}{cccc}
\hline $\begin{array}{c}\text { Ring Width size } \\
(\boldsymbol{\mu m})\end{array}$ & $\begin{array}{c}\text { Frequency } \\
(\mathbf{T H z})\end{array}$ & $\begin{array}{c}\text { Return Loss } \\
(\mathbf{d B})\end{array}$ & VSWR \\
\hline 2 & 1.021 & -39.67 & 1.30 \\
3 & 1.023 & -34.32 & 1.26 \\
4 & 1.025 & -41.23 & 1.04 \\
$\mathbf{5}$ & $\mathbf{1 . 0 2 7}$ & $\mathbf{- 6 5 . 2 6}$ & $\mathbf{1 . 0 0}$ \\
6 & 1.024 & -36.81 & 1.03 \\
7 & 1.023 & -33.99 & 1.01 \\
8 & 1.021 & -34.32 & 1.02 \\
\hline
\end{tabular}

Similar to the split width analysis, the ring width is varied and performance is analyzed. For the proposed unit cell outer ring and inner ring have the radius as $20 \mu \mathrm{m}$ and $10 \mu \mathrm{m}$ respectively. Hence it has the split ring width of $5 \mu \mathrm{m}$. Different width is changed by keeping the outer ring radius as constant. When the ring width is increased from $2 \mu \mathrm{m}$ to $5 \mu \mathrm{m}$ the return loss is enhanced after that, the return losses are reduced for $6 \mu \mathrm{m}$ and $7 \mu \mathrm{m}$. The variation in resonant frequency, return loss and VSWR while changing the split gap is listed in Table. IV.

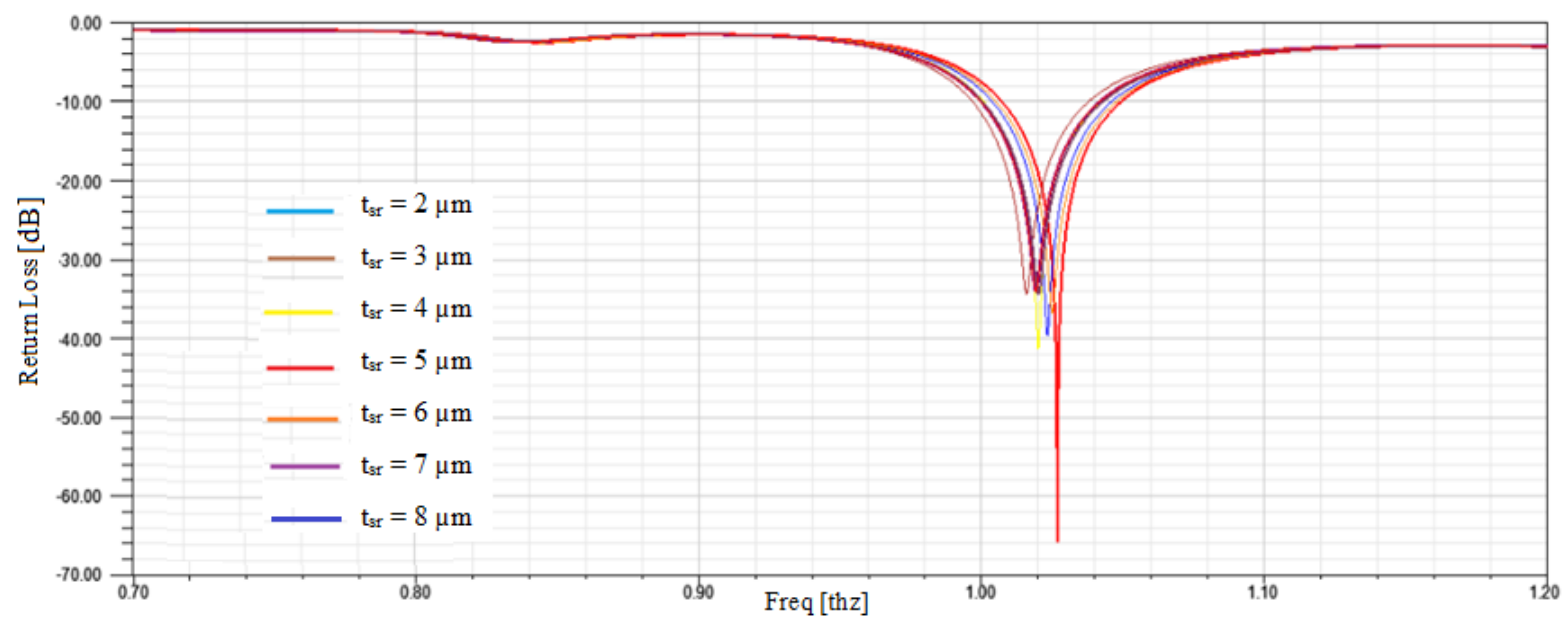

Fig. 9. Impact of return loss with respect to the ring width of the circular split ring resonator.

From the analysis, it is observed that the antenna loaded with metamaterial gives better results compared to conventional patch antenna. Parameters of the proposed $\mathrm{THz}$ antenna before and after loading the MTM are listed in Table. V. Bandwidth of the MTM antenna is improved from $13.91 \%$ to $17.95 \%$. Performance parameters of the proposed metamaterial based antenna is compared with reported antenna whose corresponding parameters are listed in Table VI.

Brazilian Microwave and Optoelectronics Society-SBMO received 27 Dec 2018; for review 27 Dec 2018; accepted 4 July 2019 Brazilian Society of Electromagnetism-SBMag 
Journal of Microwaves, Optoelectronics and Electromagnetic Applications, Vol. 18, No. 3, September 2019387 DOI: http://dx.doi.org/10.1590/2179-10742019v18i31577

TABLE V. COMPARISON RESULTS OF PARAMETERS FOR CONVENTIONAL AND WITH METAMATERIAL ANTENNA

\begin{tabular}{lcc}
\hline \multicolumn{1}{c}{ Parameters } & Conventional Antenna & MTM Antenna \\
\hline Resonant frequency $(\mathrm{THz})$ & 0.97 & 1.02 \\
Return Loss (dB) & -28.86 & -65.26 \\
Gain $(\mathrm{dB})$ & 1.44 & 5.75 \\
VSWR & 1.07 & 1.00 \\
Fractional Bandwidth $(\%)$ & $4.12 \%$ & $4.12 \%$ \\
\hline
\end{tabular}

TABLE VI. COMPARISON RESULTS OF PARAMETERS FOR PROPOSED METAMATERIAL ANTENNA WITH EXISTING ANTENNA

\begin{tabular}{|c|c|c|c|c|c|c|}
\hline & $\begin{array}{l}\text { Proposed } \\
\text { antenna }\end{array}$ & $\begin{array}{c}\text { Proposed } \\
\text { antenna } \\
\text { with SSR } \\
\end{array}$ & $\begin{array}{c}\text { Denizhan } \\
\text { Sirmaciet et } \\
\text { al, 2016 [1] }\end{array}$ & $\begin{array}{c}\text { Jeet Ghosh } \\
\text { et al, 2017 } \\
{[6]} \\
\end{array}$ & $\begin{array}{c}\text { Maria } \\
\text { Koutsoupidou } \\
\text { et al, 2014 [10] }\end{array}$ & $\begin{array}{c}\text { Li et al, } 2010 \\
{[26]}\end{array}$ \\
\hline Substrate & Quartz & Quartz & Quartz & $\begin{array}{l}\text { Silicon } \\
\text { Oxide, }\end{array}$ & Silicon & FR-4 \\
\hline Size & $\begin{array}{c}131 \times 155 \\
\mu \mathrm{m}^{2}\end{array}$ & $\begin{array}{c}128.5 \times 150 \\
\mu \mathrm{m}^{2}\end{array}$ & $180 \times 212 \mu \mathrm{m}^{2}$ & - & $\begin{array}{c}1000 \times 1000 \\
\mu \mathrm{m}^{2}\end{array}$ & $32 \times 28 \mathrm{~mm}^{2}$ \\
\hline Patch Size & $71.5 \times 95 \mu \mathrm{m}^{2}$ & $68.5 \times 90 \mu \mathrm{m}^{2}$ & $92 \times 152 \mu \mathrm{m}^{2}$ & $\begin{array}{c}136 \times 189 \\
\mu \mathrm{m}^{2}\end{array}$ & $181 \times 237 \mu \mathrm{m}^{2}$ & $16 \times 12 \mathrm{~mm}^{2}$ \\
\hline SRR & - & Circular & Rectangular & Rectangular & Square & Rectangular \\
\hline $\begin{array}{l}\text { Resonant frequency } \\
(\mathrm{THz})\end{array}$ & 1.02 & 1.02 & 1.08 & 0.46 & 1.00 & 0.006 \\
\hline Return Loss (dB) & -28.76 & -65.26 & -55 & -17.08 & -14.20 & -22 \\
\hline Gain $(\mathrm{dB})$ & 1.44 & 5.75 & 3.57 & - & 1.99 & 7.14 \\
\hline VSWR & 1.07 & 1.00 & 1.00 & - & - & 1.00 \\
\hline $\begin{array}{l}\text { Fractional } \\
\text { Bandwidth }(\%)\end{array}$ & 4.12 & 4.12 & 8.20 & 7.60 & 2 & 43.9 \\
\hline
\end{tabular}

From the Table VI it is observed that Jeet Ghosh et al, proposed miniaturized antenna but it produced the return loss of $-17.08 \mathrm{~dB}$ [6]. Antenna, which is proposed by Maria Koutsoupidou et al [10], has high directivity as $9.58 \mathrm{~dB}$. The maximum return loss of $-55 \mathrm{~dB}$ at $1.08 \mathrm{THz}$ is produced by the antenna [1], which is designed by quartz material provided with the size of $180 \mu \mathrm{m} \times 212 \mu \mathrm{m}$. The proposed antenna is designed with same material and has same size as that of the antenna reported in [1]. Even though the bandwidth of the proposed antenna is comparatively low, the remaining parameters such as return loss and gain are enhanced. Hence, the proposed antenna could be suitable for terahertz applications.

\section{CONCLUSION}

In this paper, miniaturized metamaterial antenna with the dimension of $180 \mu \mathrm{m} \times 212 \mu \mathrm{m}$ is presented for $\mathrm{THz}$ region. The proposed circular split ring resonator is integrated with patch as a ground plane. The results show that the return loss and gain are enhanced significantly at the resonant frequency of 1.02 THz. Particularly, the return loss is deep as $-65.26 \mathrm{~dB}$ at the resonant frequency. It is also shown that the gain of the antenna can be enhanced with the help of negative refractive index metamaterial. Further the impact of return loss while varying the SRR width and thickness are investigated and identified that the maximum performance is obtained when the SRR split width and split ring thickness are kept as $5 \mu \mathrm{m}$. From this analysis, the proposed antenna can be used as 
Journal of Microwaves, Optoelectronics and Electromagnetic Applications, Vol. 18, No. 3, September 2019388 DOI: http://dx.doi.org/10.1590/2179-10742019v18i31577

matching structure in the antenna design.

\section{REFERENCES}

[1] Y. Denizhan Sirmaci, C. K. Akin and C. Sabah, "Fishnet based Metamaterial loaded THz patch antenna," Optica Quantum Electronics, vol. 48, no. 2, pp. 1-10, 2016.

[2] S. U. Hwu, K. B. de Silva, and C. T. Jih, “Terahertz (THz) wireless systems for space applications," Sensors Application Symposium, pp. 171-175, 2013.

[3] B. Li, B. Wu, and C.-H. Liang, "Study on High Gain Circular Waveguide Array Antenna With Metamaterial Structure," Progress in Electromagnetics Research, vol. 60, pp. 207-219, 2006.

[4] Y. Dong, Hi. Toyao, and T. Itoh, "Compact Circularly-Polarized Patch Antenna Loaded with Metamaterial Structures," IEEE Transactions on Antennas and Propagation, vol. 59, no. 11, pp. 4329-4333, 2011.

[5] J.-S. Hong, M. J. Lancaster, "Couplings of Microstrip Square II Open-Loop Resonators for Cross-Coupled Planar Microwave Filters," ," IEEE Transactions on Terahertz Science and Technology, vol. 44, no. 12, pp. 2099-2109, 1996.

[6] P.-Y. Chen, A. Alù, “Terahertz Metamaterial Devices Based on Graphene Nanostructures," IEEE Transactions on Terahertz Science and Technology, vol. 3, no. 6, pp. 748-756, 2013.

[7] J. Ghosh and D. Mitra, "Mutual Coupling Reduction in Planar Antenna by Graphene Metasurface for THz Application,” Journal of Electromagnetic Waves and Applications, vol. 31, no. 18, pp. 2036-2045, 2017.

[8] H. Tao, N. I. Landy, C. M. Bingham, X. Zhang, R. D. Averitt, and W. J. Padilla, "A Metamaterial Absorber for the Terahertz Regime: Design, Fabrication And Characterization," Optical Society of America, vol. 16, no. 10, pp. 7181-7188, 2008.

[9] Q.-Y. Wen, H.-W. Zhang, Y.-S. Xie, Q.-H. Yang, and Y.-L. Liu, "Dual band terahertz metamaterial absorber: Design, fabrication and characterization,” Applied Physics Letter, vol. 95, no. 24, pp. 1-3, 2009.

[10] Z. Xu, X. Dong, and J. Bornemann, "Design of a Reconfigurable MIMO System for THz Communications Based on Graphene Antennas," IEEE Transactions on Terahertz Science and Technology, vol. 4, no. 5, pp. 609$617,2014$.

[11] L. Cong, Y. K. Srivastava, and R. Singh, "Near-Field Inductive Coupling Induced Polarization Control in Metasurfaces," Advanced Optical Mater, vol. 4, pp. 848-852, 2016.

[12] S. Kumar, A. Deep, K. Vellingiri and E. E. Kwon, "Metal-organic framework composites as electrocatalysts for electrochemical sensing applications," Coordination Chemistry Reviews, vol. 357, pp. 105-129, 2017.

[13] M. Koutsoupidou, I. S, Karanasiou and N. Uzunoglu, "Substrate Constructed By an Array of Split Ring Resonators for a THz Planar Antenna,” Journal of Computational Electronics, vol. 13, no. 3, pp. 593-598, 2014.

[14] Y. Lee and Y. Hao, "Characterization of Microstrip Patch Antennas on Metamaterial Substrates Loaded with Complementary Split-Ring Resonators," Microwave And Optical Technology Letters, vol. 50, no. 8, pp. 2131$2135,2008$.

[15] W. Withayachumnankul, and D. Abbott, "Metamaterials in the Terahertz Regime," IEEE Photonics Journal, vol. 1, no. 2, pp. 99-118, 2009.

[16] H. Němec, P. Kužel, F. Kadlec, C. Kadlec, R. Yahiaoui and P. Mounaix, "Tunable Terahertz Metamaterials with Negative Permeability," Physical Review B, vol. 79, no. 24, pp. 1-4, 2009.

[17] D. Catano-Ochoa, D. E. Senior, F. Lopez and E. Reyes-Vera, "Performance Analysis of a Microstrip Patch Antenna loaded with an Array of Metamaterial Resonators," IEEE International Symposium on Antennas and Propagation (APSURSI), pp. 281-282, 2016.

[18] H. Tao, W. J. Padilla, X. Zhang, and R. D. Averitt, "Recent Progress In Electromagnetic Metamaterial Devices For Terahertz Applications," IEEE Journal of Selected Topics in Quantum Electronics, vol. 17, no. 1, pp. $92-$ 101, 2011. 
Journal of Microwaves, Optoelectronics and Electromagnetic Applications, Vol. 18, No. 3, September 2019389 DOI: http://dx.doi.org/10.1590/2179-10742019v18i31577

[19] M. Koutsoupidou, N. Uzunoglu and I. S. Karanasiou, "Antennas on Metamaterial Substrates as Emitting Components for THz Biomedical Imaging," Proceedings of the 2012 IEEE 12th International Conference on Bioinformatics \& Bioengineering (BIBE), Larnaca, Cyprus, pp. 319-322, 2012.

[20] H.-J. Song, and T. Nagatsuma, "Present and Future of Terahertz Communications," IEEE Transactions on Terahertz Science and Technology, vol. 1, no. 1 pp. 256-263, 2011.

[21] A. Nejati, R. A. Sadeghzadeh, F. Geran, "Effect of Photonic Crystal and Frequency Selective Surface Implementation on Gain Enhancement in the Microstrip Patch Antenna at Terahertz Frequency," Physica B: Condensed Matter, vol. 449, pp. 113-120, 2014.

[22] Y. Ma, H.-W. Zhang, Y. Li, Y. Wang, W. Lai, “Terahertz Sensing Application By Using Fractal Geometries Of Split-Ring Resonators," Progress in Electromagnetic Research, vol. 138, pp. 407-419, 2013.

[23] D. M. Pozar, "Considerations for Millimeter Wave Printed Antennas," IEEE Transactions on Antennas and Propagation, vol. 31, no. 5, pp. 740-747, 1983.

[24] D. J. Par, J. T. Hong, J. K. Park, S. B. Choi, B. H. Son, F. Rotermund, S. Lee, K. J. Ahn, D. S. Kim and Y. H. Ahn, "Resonant Transmission of Terahertz Waves Through Metallic Slot Antennas on Various Dielectric Substrates," Current Applied Physics, vol. 13, no. 4, pp. 753-757, 2013.

[25] S. J. Park, S. A. N. Yoon, Y. H. Ahn, "Effective Sensing Volume of Terahertz Metamaterial with Various Gap Widths," Optical Society of Korea, vol. 20, no. 5, pp. 628-632, 2016.

[26] L.-W. Li, Y.-N. Li, T. S. Yeo, J. R. Mosig, O. J. F. Martin, “A broadband and high-gain metamaterial microstrip antenna," Applied Physics Letters, vol. 96, pp. 164101, 2010.

[27] G. Varamini, A. Keshtkar and M. N. Moghadasi, "Compact and miniaturized microstrip antenna based on Fractal and metamaterial loads with reconfigurable qualification," International Journal of Electronics and Communications, pp. 1-21, 2017.

[28] P. K. Singh, G. Saini, "Log - Periodic Terahertz Antenna with Square SRR Metamaterial Superstrate," International Journal of Engineering Research \& Technology, vol. 5, no. 07, pp. 527-530, 2016.

[29] A. A. A. Abdelrehim, H. Ghafouri-Shiraz, "High Performance Terahertz Antennas Based On Split Ring Resonator And Thin Wire Metamaterial Structures," Microwave and Optical Technology Letters, vol. 58, no. 2, pp. 382-389, 2015.

[30] Q.-L. Zhang, L.-M. Si, Y. Huang, Xi. Lv, and W. Zhu, "Low-index-metamaterial for gain enhancement of planar terahertz antenna," AIP Advances, vol. 4, pp. 037103:1-7, 2014.

[31] M. K. Khandelwal, B. K. Kanaujia, S. Kumar, and A. K. Gautam, "Miniaturization Of DNG Metamaterial," Microwave and Optical Technology Letters, vol. 59, no. 4, pp. 862-865, 2017.

[32] X. Chen, T. M. Grzegorczyk, B.-I. Wu, J. Pacheco, Jr., J. A. Kong, "Robust Method to Retrieve the Constitutive Effective Parameters of Metamaterials”, Physical Review E, vol. 70, pp. 1-7, 2004.

[33] R. Selvaraju, M. H. Jamaluddin, M. R. Kamarudin, J. Nasir, M. H. Dahri, "Complementary Split Ring Resonator for Isolation Enhancement in 5G Communication Antenna Array," Progress in Electromagnetics Research C, vol. 83, pp. 217-228, 2018.

[34] C. Sabah, "Microwave Response of Octagon-Shaped Parallel Plates: Low-Loss Metamaterial," Optics Communications, vol. 285, pp. 4549-4552, 2012.

[35] F. Ma, Y. -S. Lin, X. Zhang, C. Lee, “Tunable Multiband Terahertz Metamaterials Using A Reconfigurable Electric Split-Ring Resonator Array," Light: Science \& Applications, 2014.

[36] D. R. Smith, W. J. Padilla, D. C. Vier, S. C. Nemat-Nasser, S. Schultz, "Composite Medium with Simultaneously Negative Permeability and Permittivity," Physical Review Letters, vol. 84, no. 18, pp. 1-4, 2000.

[37] Y.-H. Chen, C.-C. Chen, A. Ishikawa, M.-H. Shiao, Y.-S. Lin, C.-N. Hsiao, H.-P. Chiang and T. Tanaka, "Interplay of Mutual Electric and Magnetic Couplings Between Three-Dimensional Splitting Resonators," Optical Society of America, vol. 25, no. 3, pp. 1-9, 2017. 